\title{
Enhanced Fluorescent DNA Microarray Using Optical Interference Mirror Slide
}

\author{
Mitsuru Yasuda ${ }^{\dagger}$ and Takuo Akimoto* \\ School of Bioscience and Biotechnology, Tokyo University of Technology, \\ 1404-1 Katakura, Hachioji, Tokyo 192-0982, Japan
}

(Received March 2, 2017; accepted June 1, 2017)

Keywords: DNA microarray, fluorescence enhancement, optical interference

Enhanced fluorescence using an optical interference mirror (OIM) slide consisting of a metal film and a transparent dielectric thin film is used to improve the sensitivity of a DNA microarray. Twenty-one bases of a probe DNA are immobilized on the OIM slide fabricated with $\mathrm{Ag}$ and $\mathrm{Al}_{2} \mathrm{O}_{3}$, and 21 bases of target DNA, whose sequence is complementary to that of the probe DNA, are detected. After evaluating the hybridization specificity between the probe DNA and the target DNA, the sensitivity improvement is estimated. As a result, a 50-fold improvement can be achieved compared with a bare glass slide.

\section{Introduction}

Chip-based DNA detection using a DNA microarray (or chip) has been applied in many scientific fields such as clinical diagnostics and basic research in life sciences. In DNA detection, a solid substrate is used in which different sequences of multiple single-stranded probe DNAs have been immobilized. A fluorescence signal resulting from hybridization between a single-stranded target DNA labeled with a fluorophore and a probe DNA provides information such as the concentration and sequence of a target DNA. Therefore, a sensitive measurement of fluorescence is crucial for chip-based DNA detection, and various solid substrates for enhancement of fluorescence have been developed.

Plasmonic chips, whose substrates contain immobilized metal nanoparticles, have been applied in DNA detection. A plasmonic chip can improve fluorescence owing to an electric field enhanced by localized surface plasmon resonance near metal nanoparticles. Gold nanoparticles, ${ }^{(1)}$ gold nanorods, ${ }^{(2)}$ and silver nanoislands ${ }^{(3-5)}$ have been used as materials for plasmonic chips. A 10-fold improvement of the sensitivity of chip-based DNA detection has been reported with the silver nanoisland structure. ${ }^{(4)}$ Moreover, fluorescence-enhancing substrates with nanoporous ${ }^{(6-8)}$ and nanopillar ${ }^{(9-11)}$ structures have been developed. These substrates can be fabricated on a $\mathrm{Si}$ substrate via anodization and photolithography. Surface area enlargement by nanostructures leads to an increased density of immobilized DNA and antibody molecules and results in an improved sensitivity of target molecule detection. Seven-

*Corresponding author: e-mail: akimoto@stf.teu.ac.jp

http://dx.doi.org/10.18494/SAM.2018.1589

${ }^{\dagger}$ Current address: School of Science and Technology, Kwansei Gakuin University, 2-1 Gakuen, Sanda, Hyogo 669-1337, Japan 
fold ${ }^{(8)}$ and 34 -fold ${ }^{(10)}$ improvements of sensitivity were reported for the nanoporous and nanopillar substrates, respectively.

An optical interference mirror (OIM) slide consisting of a multilayered structure with a metal film and a transparent dielectric thin film has been reported to provide a 100fold enhancement of fluorescence from a fluorophore placed on the thin film. ${ }^{(12,13)}$ This enhancement was explained with a waveguide mode channeled within the thin film ${ }^{(12,13)}$ and with a double interference of excitation and emission in the thin film. ${ }^{(14)} \mathrm{Ag} / \mathrm{LiF},{ }^{(12,13)} \mathrm{Ag} /$ $\mathrm{Al}_{2} \mathrm{O}_{3},{ }^{(14-16)} \mathrm{Si} / \mathrm{SiO}_{2},{ }^{(17,18)}$ and $\mathrm{Ag} /$ organic film ${ }^{(19)}$ structures have been developed for OIM slides. A 71-fold sensitivity improvement for fluorescently labeled streptavidin detection through biotin immobilized on a $\mathrm{Ag} / \mathrm{Al}_{2} \mathrm{O}_{3}$ OIM slide has been demonstrated. ${ }^{(20)}$ In addition to streptavidin detection, a sensitive detection of a mutagen using genetically modified Escherichia coli (E. coli) has been demonstrated using a $\mathrm{Ag} / \mathrm{Al}_{2} \mathrm{O}_{3}$ OIM slide. ${ }^{(21)}$ Moreover, in recent years, high-contrast fluorescence imaging using a $\mathrm{Ag} / \mathrm{Al}_{2} \mathrm{O}_{3}$ OIM slide has been proposed. ${ }^{(22,23)}$ As seen above, the basic properties of the $\mathrm{Ag} / \mathrm{Al}_{2} \mathrm{O}_{3}$ OIM slide are well known, and bioassays using the $\mathrm{Ag} / \mathrm{Al}_{2} \mathrm{O}_{3} \mathrm{OIM}$ slide have already been demonstrated. Herein, we report an enhanced fluorescence DNA microarray for chip-based DNA detection using a $\mathrm{Ag} / \mathrm{Al}_{2} \mathrm{O}_{3}$ OIM slide.

\section{Materials and Methods}

\subsection{Reagents, proteins, and buffers}

(3-Aminopropyl)trimethoxysilane (APTMS) and streptavidin were obtained from SigmaAldrich Co. (MO, USA). Biotin $N$-hydroxysulfosuccinimide ester (sulfo-NHS biotin derivative) was obtained from Dojindo Laboratories (Kumamoto, Japan). Bovine serum albumin (BSA) was obtained from Wako Pure Chemical Industries (Osaka, Japan).

Tris- $\mathrm{HCl}$ ( $\mathrm{pH}$ 7.4) containing $10 \mathrm{mM}$ Tris (2-amino-2-hydroxymethyl-1,3-propanediol), Trisethylenediaminetetraacetic acid (TE) containing $1 \mathrm{mM}$ ethylenediamine- $N, N, N^{\prime}, N$ '-tetraacetic acid in Tris-HCl, sodium chloride-TE (STE) containing $100 \mathrm{mM} \mathrm{NaCl}$ in TE, and STE-sodium dodecyl sulfate (SDS) containing $0.2 \%$ SDS in STE were prepared.

\subsection{Oligonucleotides}

Invasion A (invA) in Salmonella enterica subspecies enterica serovar Typhimurium and verotoxin 2 (VT2) in enterohemorrhagic E. coli O157:H7 were used as model DNA sequences, and four types of oligonucleotides consisting of 21 bases were synthesized by Tsukuba Oligo Service (Ibaraki, Japan). The sequences of the synthesized oligonucleotides are presented in Table 1. An invA probe DNA is completely complementary to the sequence of an invA target DNA. In contrast, a VT2 probe DNA is not completely complementary to an invA target DNA.

\subsection{Fabrication of the OIM slide}

Glass microscope slides were used as a solid fabrication support for the OIM slide. Each glass slide was first sonicated in continuous ethanol and $\mathrm{H}_{2} \mathrm{O}$ for $1 \mathrm{~h}$, rinsed with $\mathrm{H}_{2} \mathrm{O}$, and 
Table 1

Synthesized oligonucleotide.

\begin{tabular}{lc}
\hline Name & Sequences (5' to 3') \\
\hline Cy5-labeled invA target DNA & Cy5-GATGAGTATTGATGCCGATTT \\
Unlabeled invA DNA probe & AAATCGGCATCAATACTCATC \\
Biotin-labeled $i n v A$ DNA probe & Biotin-AAATCGGCATCAATACTCATC \\
Biotin-labeled VT2 DNA probe & Biotin-CGTTGCAGAGTGGTATAACTG \\
\hline
\end{tabular}

then dried in an oven at $100{ }^{\circ} \mathrm{C}$. Sputtering equipment (CFS-4ES-231, Shibaura Mechatronics) was used to form the OIM structure on the slide. OIM slides were fabricated by depositing $\mathrm{Ag}$ and continuously depositing $\mathrm{Al}_{2} \mathrm{O}_{3}$ on glass slides. The adhesiveness of $\mathrm{Ag}$ was improved by depositing Cr between it and the glass slide. The thickness of the Ag layer measured using a surface profile meter (Dektak8, Veeco) was $1 \mu \mathrm{m}$. The thickness of the $\mathrm{Cr}$ layer was estimated to be $15 \mathrm{~nm}$ using a calibration between the sputtering time and the thickness measured with the surface profile meter. The thickness of the $\mathrm{Al}_{2} \mathrm{O}_{3}$ layer was determined using an ellipsometer (ESM-1T, ULVAC). The surface roughness of the OIM slide was measured using the surface profile meter (Dektak8, Veeco).

\subsection{Design of $\mathrm{Al}_{2} \mathrm{O}_{3}$ thickness}

The maximum enhancement of a fluorescence signal requires an optimal $\mathrm{Al}_{2} \mathrm{O}_{3}$ thickness to be designed, because the enhancement of a fluorescence signal using the OIM slide depends on the thickness of the $\mathrm{Al}_{2} \mathrm{O}_{3}$ layer. The $\mathrm{Al}_{2} \mathrm{O}_{3}$ layer thickness for the maximum fluorescence enhancement can be estimated on the basis of optical interference theory, ${ }^{(14)}$ and calculated to be $103 \mathrm{~nm}$. Thus, we fabricated an OIM slide with an $\mathrm{Al}_{2} \mathrm{O}_{3}$ thickness of $100 \mathrm{~nm}$ in our experiments.

\subsection{Immobilization of a probe DNA}

An experimental protocol of DNA detection is shown in Fig. 1. OIM slides were firstly aminated by incubation in 1\% APTMS diluted with $\mathrm{H}_{2} \mathrm{O}$ for $1.5 \mathrm{~h}$ at room temperature, ${ }^{(20,24)}$ washed in $\mathrm{H}_{2} \mathrm{O}$ for $10 \mathrm{~min}$, and then dried in an oven for $10 \mathrm{~min}$ at $110{ }^{\circ} \mathrm{C}$. All experiments reported in this section were performed at room temperature.

To immobilize a probe DNA on the slide surface via the biotin-streptavidin binding, the OIM slide surface was firstly covered with biotin. For this, the aminated OIM slides were immersed in $500 \mu \mathrm{M}$ sulfo-NHS biotin derivative dissolved in $\mathrm{H}_{2} \mathrm{O}$ for $1 \mathrm{~h}$. After washing in $\mathrm{H}_{2} \mathrm{O}$ for 10 min, the OIM slides were dried. Next, streptavidin was coated on the slide surface by immersing the biotinylated OIM slides in $100 \mathrm{nM}$ streptavidin dissolved in the Tris- $\mathrm{HCl}$ buffer for $1 \mathrm{~h}$.

Ten $\mathrm{nl}$ of biotin-labeled invA probe DNA ranging between 0 to $50 \mathrm{nM}$ dissolved in a TE buffer was arrayed onto the streptavidin-coated OIM slides using a DNA arrayer (BioChipArrayer, PerkinElmer). The radius of the DNA droplet was $200 \mathrm{~mm}$, and 54 droplets were arrayed on the OIM slide in $30 \mathrm{~min}$. The OIM slides were subsequently immersed in $10 \mathrm{mg} / \mathrm{ml}$ of BSA dissolved in $\mathrm{H}_{2} \mathrm{O}$ for $1 \mathrm{~h}$, washed in $\mathrm{H}_{2} \mathrm{O}$ for 10 min, and then dried. 


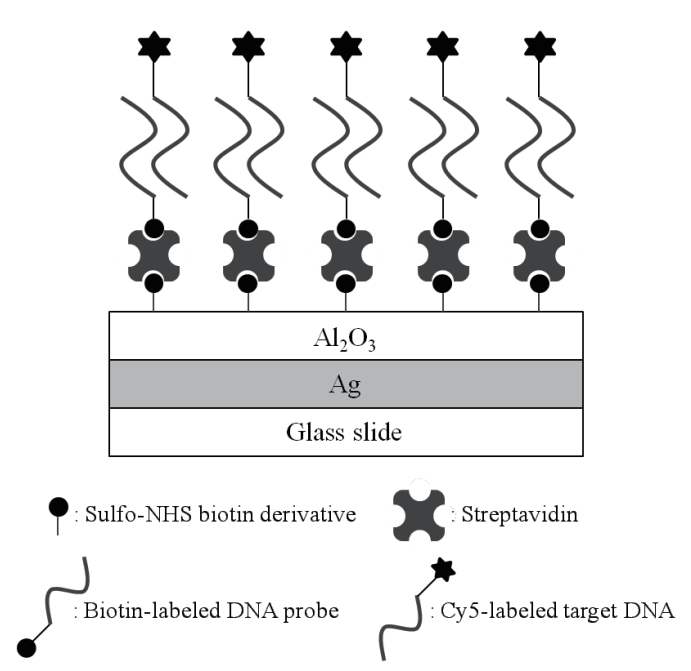

Fig. 1. Schematic illustration of probe DNA immobilization and target DNA detection.

The same immobilization procedure of probe DNA was performed for the bare glass slide to estimate the fluorescence enhancement of the OIM slide.

\subsection{DNA hybridization}

The biotin-labeled invA probe DNA-immobilized OIM slides were incubated in $50 \mathrm{nM}$ Cy5labeled invA target DNA dissolved in the STE-SDS buffer at $45^{\circ} \mathrm{C}$. After $2 \mathrm{~h}$, the OIM slides were continuously washed in the order of STE-SDS for $5 \mathrm{~min}$.

Fluorescence from Cy5 was imaged using a fluorescence scanner (Typhoon 9410, GE Healthcare UK). Fluorescence images obtained were then analyzed using the software ImageQuant TL provided by the manufacturer.

\section{Results and Discussion}

\subsection{Verification of probe DNA immobilization}

Immobilization of the probe DNA was firstly verified using $50 \mathrm{nM}$ biotin-labeled and unlabeled invA probe DNAs. The probe DNAs were immobilized on a streptavidin-coated bare glass slide. The glass slide immobilized with the probe DNA was immersed in $50 \mathrm{nM}$ Cy5labeled invA target DNA.

Figure 2 shows fluorescence signals obtained using the labeled and unlabeled probe DNAs. The fluorescence signal from the unlabeled probe DNA was sufficiently weaker than that from the labeled probe DNA. This indicates that the unlabeled probe DNA did not bind to the glass surface. The weaker fluorescence signal of the unlabeled probe DNA is from the nonspecific adsorption of the target DNA on the glass slide. Thus, it is confirmed that the labeled probe DNA can be immobilized on the OIM slide via the biotin-streptavidin binding. 


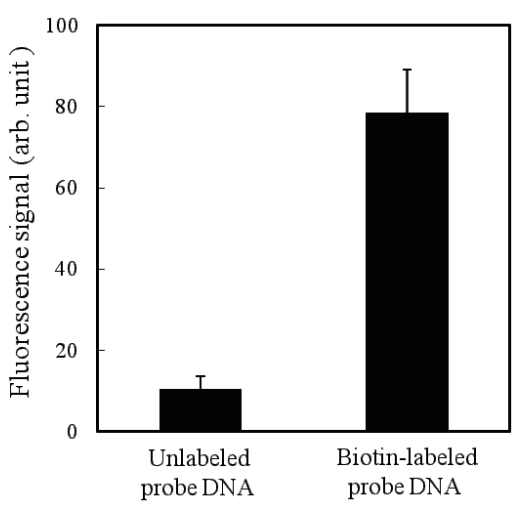

Fig. 2. Verification of the probe DNA immobilization. $50 \mathrm{nM}$ unlabeled and biotin-labeled probe DNA samples were spotted on the aminated slide. $50 \mathrm{nM}$ target DNA, which is fully matched to the probe DNAs, was measured.

\subsection{Specificity of DNA hybridization}

The specificity of target DNA detection was evaluated using the immobilized biotin-labeled invA and VT2 probe DNAs. The sequence of the VT2 probe DNA did not completely match with that of the invA target DNA. Figure 3 shows fluorescence signals from the VT2 and invA probe DNAs. Because the fluorescence signal from the VT2 probe DNA was significantly small, hybridization between the invA probe DNA and the invA target DNA was specific. Moreover, it can be confirmed that the immobilization of the probe DNA via the biotinstreptavidin binding maintains the ability of the probe DNA to hybridize with the target DNA.

\subsection{Detection of target DNA}

The invA target DNA was detected using the OIM slide immobilized with the invA probe DNA. The concentration of the probe DNA was $0-50 \mathrm{nM}$ and that of the target DNA was 50 nM. For comparison, target DNA detection was performed using the glass slide immobilized with the probe DNA.

Figure 4(a) shows the fluorescence images of the target DNA detected using the OIM and glass slides. These images were obtained with the same excitation light intensity and detector sensitivity for both slides. The fluorescence signal using the glass slide was weak, whereas the signal using the OIM slide can be clearly observed owing to the enhanced fluorescence. Figure 4(b) shows the fluorescence signal as a function of probe DNA concentration. The linear increase in fluorescence intensity with increasing probe DNA concentration can be observed with the OIM and glass slides. The linear increase indicates that the number of probe DNA molecules immobilized on the slides increased linearly. Although the linear increase in fluorescence intensity using the glass slide could be observed, the increase was difficult to see from Fig. 4(b). This is because the fluorescence of the glass slide was weaker than that of the OIM slide. 


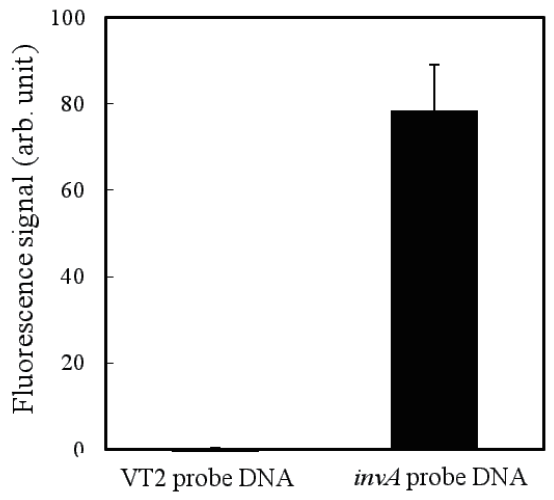

Fig. 3. Specificity of DNA hybridization. The invA probe DNA $(50 \mathrm{nM})$ was completely complementary to the target DNA $(50 \mathrm{nM})$. The VT2 probe DNA $(50 \mathrm{nM})$ was not completely complementary to the target DNA $(50 \mathrm{nM})$.

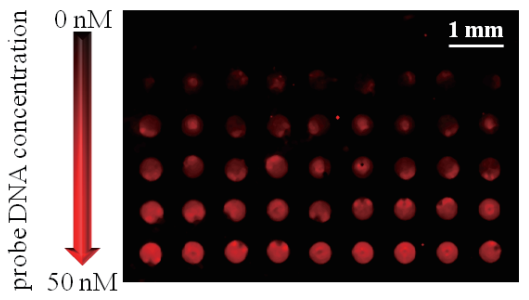

OIM slide

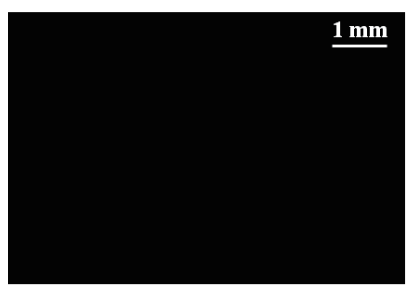

Glass slide

(a)

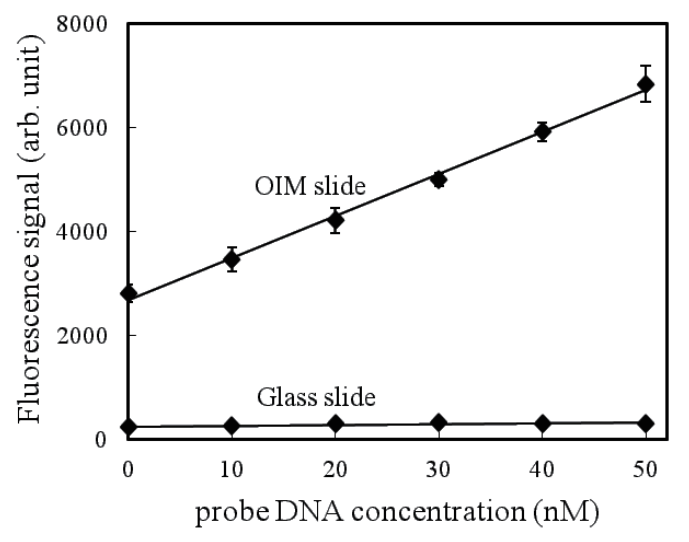

(b)

Fig. 4. (Color online) (a) Fluorescence images of $50 \mathrm{nM}$ target DNA detection with the OIM and glass slides obtained with the same excitation light intensity and detector sensitivity. The fluorescence signal using the glass slide was weak, whereas the signal using the OIM slide can be clearly observed owing to the enhanced fluorescence. (b) Fluorescence signal from $50 \mathrm{nM}$ target DNA as a function of immobilized probe DNA concentrations. Linear approximations for the OIM slide and glass slide were $y=81 x+2681$ and $y=1.6 x+245$, respectively.

The background signal, which is shown as the fluorescence signal at a probe DNA concentration of $0 \mathrm{nM}$, was also enhanced by the OIM slide. An approximately 10-foldincreased background signal was observed with the OIM slide compared with the glass slide. The relatively high magnitude of the background signal was due to the fluorescence enhancement of the OIM slide and the enhanced adsorption of the target DNA on the OIM slide surface. To investigate the adsorption of the target DNA on the OIM slide, the surface profiles of the OIM and bare glass slides were determined using a surface profile meter and are shown in Fig. 5. The surface of the OIM slide is shown to be rougher than that of the bare glass slide. Average differences between peaks and valleys were 1.7 and $0.6 \mathrm{~nm}$ for the OIM and bare glass slides, respectively. This relatively high surface roughness leads to an enlargement of the surface area and results in an increase in the nonspecific adsorption of the target DNA. 


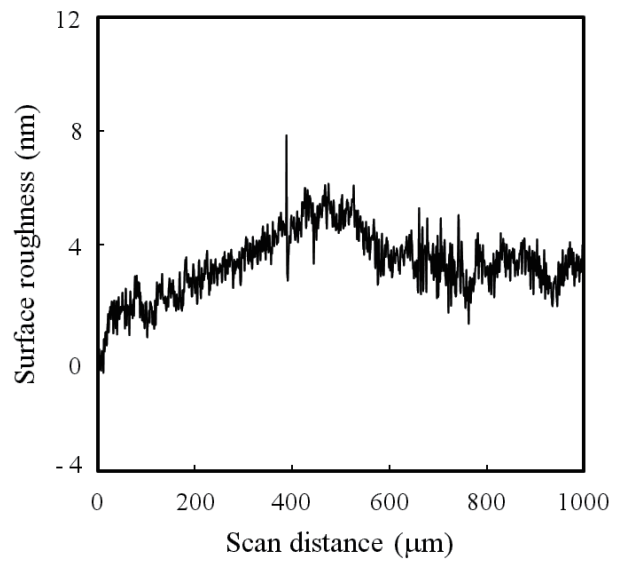

(a)

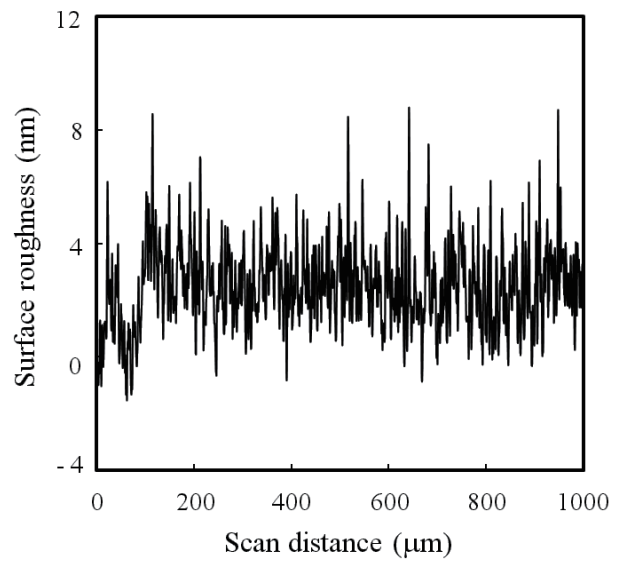

(b)

Fig. 5. Surface roughness of (a) bare glass and (b) the OIM slide.

While the background signal was enhanced using the OIM slide, the sensitivity improvement for DNA detection using the OIM slide was evaluated by comparing the slope of its linear approximation with that obtained using the bare glass slide. Because the slopes of the OIM and bare glass slides were 81 and $1.6 \mathrm{nM}^{-1}$, respectively, the sensitivity improvement can be calculated as being 50-fold. Moreover, the fluorescence enhancement at a probe DNA concentration of $50 \mathrm{nM}$ was 50 -fold compared with that of the bare glass slide after subtracting the background signal from the fluorescence signal. Thus, we succeeded in demonstrating an enhanced fluorescence DNA microarray using the OIM slide.

The sensitivity improvement for Cy5-labeled streptavidin detection using the OIM slide was reported to be 71 -fold ${ }^{(20)}$ compared with that using the bare glass slide. Therefore, a 50 -fold sensitivity improvement for DNA detection can be considered reasonable. However, a relatively high amplitude of the background signal was not observed for Cy5-labeled streptavidin detection using the OIM slide. This indicated that the BSA blocking reagent was not sufficient for DNA detection. Because the surface roughness of the OIM slide was higher than that of the bare glass slide, a more effective blocking reagent is preferable for the OIM slide.

\section{Conclusions}

An enhanced fluorescence detection of a Cy5-labeled target DNA was demonstrated using an OIM slide immobilized with a probe DNA that has a complementary sequence to that of a target DNA. The immobilization of the probe DNA and the specificity of hybridization between the probe DNA and target DNA were verified before the detection of the target DNA. When the fluorescence signal for target DNA detection using the OIM slide was compared with that using a glass slide, an enhancement of the background signal was observed owing to the fluorescence enhancement effect by the OIM slide and its surface roughness. While the background was enhanced using the OIM slide, a 50-fold sensitivity improvement for target DNA detection was 
obtained. Moreover, the fluorescence signal of the OIM slide achieved 50-fold enhancement for the target DNA of $50 \mathrm{nM}$. Thus, we demonstrated an enhanced fluorescence DNA microarray by taking advantage of fluorescence enhancement using the OIM slide.

\section{Acknowledgments}

This work was supported by the Japan Society for the Promotion of Science (JSPS) KAKENHI Grant Number 26350518.

\section{References}

1 K. Aslan, S. N. Malyn, and C. D. Geddes: J. Fluoresc. 17 (2007) 7.

2 R. Bardhan, N. K. Grady, J. R. Cole, A. Joshi, and N. J. Halas: ACS Nano. 3 (2009) 744.

3 E. G. Matveeva, I. Gryczynski, A. Barnett, Z. Leonenko, J. R. Lakowicz, and Z. Gryczynski: Anal. Biochem. 363 (2007) 239.

4 C. R. Sabanayagam and J. R. Lakowicz: Nucleic Acids Res. 35 (2007) e13.

5 J. R. Lakowicz, K. Ray, M. Chowdhury, H. Szmacinski, Y. Fu, J. Zhang, and K. Nowaczyk: Analyst 133 (2008) 1308.

6 F. Bessueille, V. Dugas, V. Vikulov, J. P. Cloarec, E. Souteyrand, and J. R. Martin: Biosens. Bioelectron. 21 (2005) 908.

7 R. Ressine, D. Finnskog, J. Malm, C. Becker, H. Lilja, G. M. Varga, and T. Laurell: J. Nanobiotechnol. 1 (2005) 93.

8 P. Takmakov, I. Vlassiouk, and S. Smirnov: Anal. Bioanal. Chem. 385 (2006) 954.

9 J. Shi, C. Peroz, D. Peyrade, J. Salari, M. Belotti, W. H. Huang, and Y. Chen: Microelectron. Eng. 83 (2006) 1664.

10 K. Kuwabara, M. Ogino, T. Ando, and A. Miyauchi: Appl. Phys. Lett. 93 (2008) 033904.

11 B. R. Murthy, J. K. K. Ng, E. S. Selamat, N. Balasubramanian, and W. T. Liu: Biosens. Bioelectron. 24 (2008) 723.

12 W. R. Holland and D. G. Hall: Opt. Lett. 10 (1985) 414.

13 K. G. Sullivan, O. King, C. Sigg, and D. G. Hall: Appl. Opt. 33 (1994) 2447.

14 T. Akimoto and M. Yasuda: Appl. Opt. 49 (2010) 80.

15 E. L. Moal, E. Fort, S. L.-Fort, F. P. Cordelières, M.-P. F.-Aupart, and C. Ricolleau: Biophys. J. 92 (2007) 2150.

16 T. Akimoto, M. Yasuda, and I. Karube: Appl. Opt. 47 (2008) 3789.

17 C. Oillic, P. Mur, E. Blanquet, G. Delapierre, F. Vinet, and T. Billon: Biosens. Bioelectron. 22 (2007) 2086.

18 V. Marino, C. Galati, and C. Arnone: J. Biomed. Opt. 13 (2008) 054060.

19 K. Yano, K. Yamano, A. Iwasaki, T. Akimoto, H. Miyachi, and A. Hiratsuka: Sens. Mater. 27 (2015) 859.

20 M. Yasuda and T. Akimoto: Anal. Sci. 28 (2012) 947.

21 H. Etoh, M. Yasuda, and T. Akimoto: Anal. Sci. 27 (2011) 1179.

22 M. Yasuda and T. Akimoto: Biosensors 4 (2014) 513.

23 M. Yasuda and T. Akimoto: Anal. Sci. 31 (2015) 139.

24 L. S. A. Prado, M. Sriyai, M. Ghislandi, A. Barros-Timmons, and K. Schulte: J. Braz. Chem. Soc. 21 (2010) 2238. 